\title{
Open vs Percutaneous TOPAZ Coblation for the Management of Plantar Fasciitis: Comparison of the Two Techniques in Obese Patients
}

\author{
PNG Wenxian ${ }^{1}$, Kevin Koo Oon Thien ${ }^{2}$
}

\begin{abstract}
Introduction: Plantar fasciopathy is known to be the most common cause of heel pain. Obese patients are known to have an increased probability of suffering from this condition. The technique of radiofrequency (RF) coblation, comparing open vs percutaneous methods, and its outcomes, has not been studied in the subgroup of patients.

Materials and methods: Patients treated operatively by RF coblation in our institution for plantar fasciitis between 2007 and 2015 were grouped into whether they received the open or percutaneous microtenotomy. The patients were interviewed at baseline and 3 months, 6 months, and 12 months postoperatively using the American Orthopedic Foot and Ankle Society (AOFAS) and 36-item Medical Outcomes Short Form (SF-36) questionnaires.

Results: Patients in both arms had an overall improvement in the visual analog scale (VAS) pain score and AOFAS ankle-hindfoot scores. The SF-36 scores also showed improvement across all areas postoperatively. There was also a significant improvement in expectation and satisfaction scores. However, those who had open RF microtenotomy fared better at 3 months, with regard to the visual analog score and both at 3 months and 6 months for the AOFAS hindfoot scores. There were no difference comparing both techniques with regard to the SF-36 scores.

Conclusion: Radiofrequency microtenotomy is a safe and effective procedure for the treatment of plantar fasciitis even in the obese group of patients. Both open and percutaneous methods have achieved good patient outcomes and expectation, although the open group showed superior pain and functional outcomes at early follow-up.

Keywords: Obesity, Open, Percutaneous, Plantar fasciitis, Radiofrequency coblation.

Journal of Foot and Ankle Surgery (Asia Pacific) (2020): 10.5005/jp-journals-10040-1121
\end{abstract}

\section{INTRODUCTION}

Plantar fasciitis is associated with pain and discomfort in the heel due to "fasciosis" at the insertion of the plantar fascia to the calcaneum. It is one of the frequent causes of heel pain, with up to $22 \%$ in runners suffering from this condition. ${ }^{1}$ Lemont et al. described the condition more as a fasciosis, with more findings of thickened and degenerate tissue compared to inflammatory changes. $^{2}$

Patients often do not seek specialist review in the orthopedic clinic unless they have recalcitrant symptoms. Majority of patients, up to $90 \%$, with plantar fasciitis (PF) will have resolution of their symptoms at around 12 months with conservative treatment. ${ }^{3}$ The nonoperative treatment of plantar fasciitis includes antiinflammatory medications, tendo-Achilles and plantar fascia stretching, steroid injections, shoe inserts, casting, night splints, and extracorporeal shock wave therapy. Surgical intervention can be an option after 6-12 months of failed conservative treatment.

The traditional method of planar fascia release has its successes but is also known to have a few undesirable effects, namely, long postsurgical recovery time, fascia rupture, and instability of the foot arches. ${ }^{4-6}$ More recently, radiofrequency (RF) coblation is used as a minimally invasive therapy for chronic plantar fasciitis. This treatment works by causing tissue destruction with little heat damage and healing taking place via controlled inflammation and targeted angiogenesis. This technique can be administered using the open or percutaneous (minimally invasive) approach, with
1,2Department of Orthopedic Surgery, Singapore General Hospital, Singapore

Corresponding Author: PNG Wenxian, Department of Orthopedic Surgery, Singapore General Hospital, Singapore, Phone: +65 98361145, e-mail: wenxian.png@mohh.com.sg

How to cite this article:Wenxian PNG, Thien KKO. Open vs Percutaneous TOPAZ Coblation for the Management of Plantar Fasciitis: Comparison of the Two Techniques in Obese Patients. J Foot Ankle Surg (Asia Pacific) 2020;7(1):14-20.

Source of support: Nil

Conflict of interest: None

some studies showing the open technique to have superior early outcomes. $^{7-9}$

Body mass index (BMI) has been frequently associated with plantar fasciitis, though the exact mechanism for the association is uncertain. It is known that overweight or obese patients have up to a 1.4 times increased chance of suffering from plantar fasciitis ${ }^{10-11}$ Understanding obesity as an etiology for plantar fasciitis may affect management strategies. The technique of RF coblation has not been studied in the subgroup of patients who are overweight and obese. The aim of this retrospective study is to compare the open and the minimally invasive method of RF microtenotomy in the management of plantar fasciitis in the subgroup of obese patients as well as assess its long-term outcome over a 1 year follow-up.

() The Author(s). 2020 Open Access This article is distributed under the terms of the Creative Commons Attribution 4.0 International License (https://creativecommons. org/licenses/by-nc/4.0/), which permits unrestricted use, distribution, and non-commercial reproduction in any medium, provided you give appropriate credit to the original author(s) and the source, provide a link to the Creative Commons license, and indicate if changes were made. The Creative Commons Public Domain Dedication waiver (http://creativecommons.org/publicdomain/zero/1.0/) applies to the data made available in this article, unless otherwise stated. 


\section{Materials and Methods}

\section{Patient Selection}

The patients included in the study was from a database provided by our institution's Orthopaedic Diagnostic Centre. Data from all patients with plantar fasciotomy at our institution from December 2007 to September 2013 were considered for the analysis. Forty-five patients had complete follow-up data at 1 year postoperatively and they were analyzed for our study. Our selection criteria enrolled in the study only participants who have been symptomatic for at least 6 months, have undergone but failed conservative treatment, and have a $\mathrm{BMI}$ of $>25.0$. Our exclusion criteria consist of patients who have diabetes mellitus, $\mathrm{BMI}$ of $<25$, coagulopathy, peripheral vascular disease, infection, autoimmune disease, tumor, or had prior surgery to the same plantar fascia (Table 1). Evaluation of the patients preoperatively and perioperative management were identical for both populations. All surgeries were performed by senior orthopedic surgeons in the institution.

\section{Operative Intervention}

Based on surgeon and patient preference, surgery will be performed either with the open method or with the percutaneous method of RF ablation. The surgeons were adept with both techniques. Patients were told to expect a 3-cm wound for open RF microtenotomy and alternating small puncture wounds for the percutaneous procedure. For both procedures, patients were counseled to be discharged on the same day and postoperatively were allowed to fully bear weight as tolerated. Both procedures were performed under regional or general anesthesia. Preoperatively, the patient would indicate the most painful part of his or her heel, and the area was marked out. The details of open or percutaneous RF microtenotomy are briefly described below.

\section{TOPAZ Microtenotomy Machine}

We performed the RF-based microtenotomy procedure using the TOPAZ MicroDebrider device (ArthroCare, Sunnyvale, CA), connected to a System 2000 generator set at setting 4 (175V-RMS). This device uses an RF-based (coblation) process in a controlled plasma environment. The RF energy excites electrolytes in an electrolyte (saline) conductive solution, and this generates radicals within precisely focused plasma. The energized particles in the plasma generate adequate energy to disrupt covalent molecular bonds, and this results in the ablation of soft tissues at relatively low temperatures (typically $40-70.8^{\circ} \mathrm{C}$ ). ${ }^{12,13}$

Table 1: Study selection criteria

\begin{tabular}{l}
\hline \multicolumn{1}{c}{ Selection criteria } \\
\hline Inclusion \\
Chronic plantar fasciitis for $>6$ months recalcitrant to \\
conservative treatment \\
$\mathrm{BMI}>30$ \\
$\mathrm{Age}>18$ years and $<80$ years \\
Full set of outcome data for 1 year \\
Exclusion \\
Lost to follow-up \\
Diabetes mellitus, coagulopathy, infection, tumor, peripheral \\
vascular disease, autoimmune disease, prior surgery to the foot \\
Incomplete data set
\end{tabular}

The tip of the TOPAZ device has a surface area of $0.502 \mathrm{~mm}^{2}$ and is about $0.8 \mathrm{~mm}$ in diameter. Following an incision on the plantar surface of the heel in the open technique, or a puncture wound in the percutaneous technique, the tip of the TOPAZ device is targeted to the region on the plantar fascia where there is most tenderness. The surgeon would activate the device for $500 \mathrm{~ms}$, and the TOPAZ probe would move in a grid-like pattern with $5 \mathrm{~mm}$ intervals, with a depth of 3-5 mm within the fascia. If the microdebridements are performed at too close intervals, this would risk a rupture of the fascia. As such, a procedure with the TOPAZ microtenotomy would result in around 10-20 microdebridements to the plantar fascia.

\section{Open Microtenotomy}

A longitudinal incision of around $2-3 \mathrm{~cm}$ was made over the area of the foot that was most tender, and dissection of the tissues were made down to the plantar fascia (Fig. 1). After initiating sterile isotonic saline flow from a line connected to the RF system, the microtenotomy tip was then placed on the fascia and microdebridements were carried out in a grid-like fashion. After debridement, the wound was irrigated and closed in layers.

\section{Percutaneous Microtenotomy}

The most tender part of the heel was marked out before induction of anesthesia. A 2-mm K-wire was used to puncture the skin in a grid-like pattern about $5 \mathrm{~mm}$ apart (Fig. 2). The TOPAZ tip would be inserted through the puncture wound to a depth of about 3-5 $\mathrm{mm}$ into the fascia. The probe would then be activated for the RF microtenotomy to take place.

\section{Outcome Measures}

The primary aim of the study was to determine the pain scores and functional outcomes of the subset of overweight and obese patients undergoing plantar fasciotomy for up to 1 year postoperatively. The clinical data analyzed in our study were from our institution's Orthopaedic Diagnostic Centre during the follow-up visits, whereby patient-administered questionnaire was conducted.

The data collected included procedure performed, demographics, height, and weight. Our assessment included the American Orthopedic Foot and Ankle Society (AOFAS) anklehindfoot scale, the AOFAS component of the visual analog scale (VAS) pain score (HINDVAS), and the 36-item (SF-36) health survey results. The patients were also asked two questions adapted

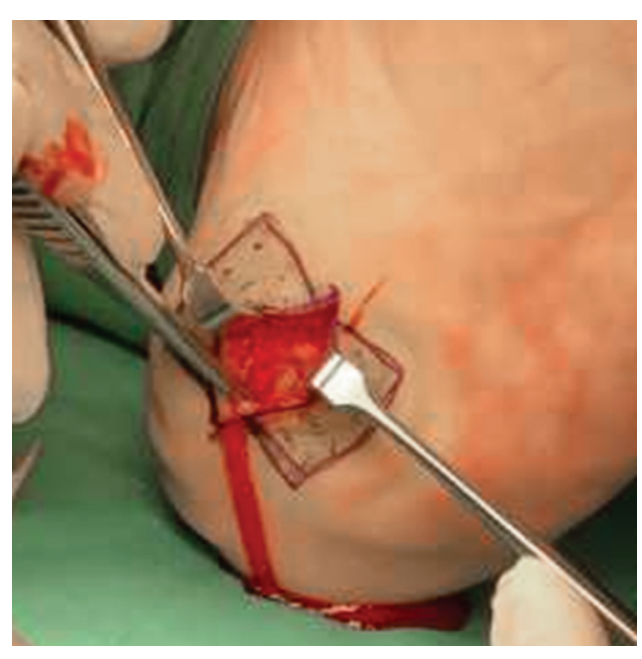

Fig. 1: Open technique with direct vision of the plantar fascia 


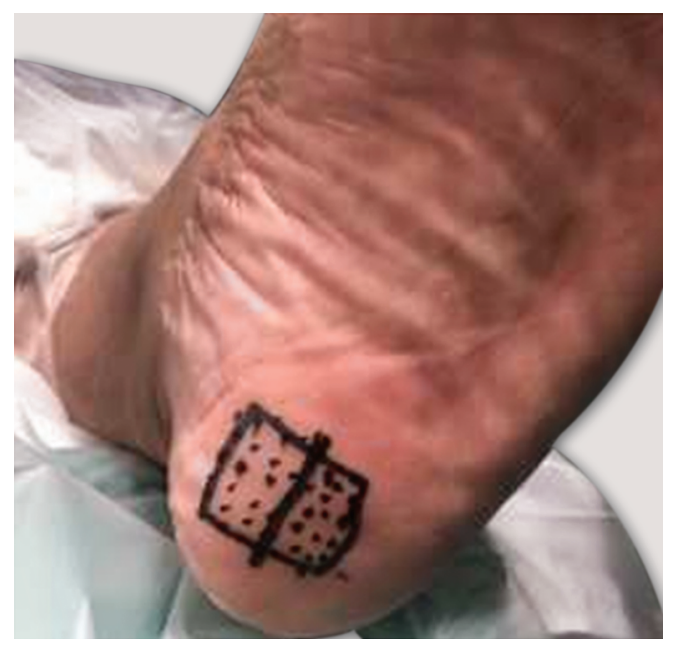

Fig. 2: Percutaneous technique with preoperative marking in a grid-like fashion of about $5 \mathrm{~mm}$ apart representing where the radiofrequency probe would puncture

from the North American Spine Society low back pain instrument about expectations (EXP) and satisfaction (SAT) about their surgery. Satisfaction was measured from 1-6, with 1 representing excellent satisfaction and 6 poor satisfaction. Expectation was measured from 1-7, with 1 representing expectations fully met and 7 expectations not met at all. The complications that were assessed included infection, osteomyelitis, wound dehiscence, pain recurrence, hypertrophic scar formation, and/or iatrogenic injury to the nerves, vessels, or bones. The patients were assessed preoperatively during their hospitalization and postoperatively at 3 and 6 months and 1 year.

\section{Statistical Analysis}

All statistical analyzes were performed using SPSS version 21 (SPSS, Inc.; IBM Company, Chicago, IL), and $p \leq 0.05$ was considered significant. This was a retrospective study, and hence, there was no prestudy sample size calculation performed. Fisher's exact tests, Student's $t$ test, Mann-Whitney test, and $\chi^{2}$ test were used in the statistical analyzes of the variables.

\section{Results}

Forty-five patients who met our BMI inclusion criteria and had completed follow-up of 1 year with a complete data set were included in our study. Six (13.3\%) patients underwent operations for both feet at the same setting. The median age was 46 years and with more females ( $n=26,57.77 \%$ ) as compared to males ( $n=19,42.22 \%$ ). Nineteen patients underwent percutaneous RF microtenotomy and 26 underwent the open procedure. There were a total of 20 right (44.4\%) and 19 left feet (42.2\%). There were no difference in BMI ( $28.4 \mathrm{~kg} / \mathrm{m}^{2}$ in percutaneous RF microtenotomy and $29.6 \mathrm{~kg} / \mathrm{m}^{2}$ in open RF microtenotomy; $p=0.416)$. Demographic characteristics are summarized in Table 2.

Analyzed as two separate groups, our results show that both techniques for RF microtenotomy showed an improvement in all functional scores, including the HINDVAS and AOFAS anklehindfoot score (HINDTOT) (Table 3). The SF-36 scores also showed improvement across all areas postoperatively (Figs 3 and 4). Both SAT and EXP were measured postoperatively and hence no comparison with preoperative scores were made. The mean

\begin{tabular}{lllll} 
Table 2: Patient's demographics & & & \\
\hline Variable & $\begin{array}{l}\text { Total } \\
(n=45)\end{array}$ & $\begin{array}{l}\text { Open } \\
(n=26)\end{array}$ & $\begin{array}{l}\text { Percutaneous } \\
(n=19)\end{array}$ & p value \\
\hline $\begin{array}{l}\text { Age (years) } \\
\text { Laterality }\end{array}$ & 46.45 & 47.15 & 46.05 & 0.344 \\
$\quad$ Right & 20 & 11 & 9 & 0.272 \\
$\quad$ Left & 19 & 11 & 8 & 0.274 \\
$\quad$ Bilateral & 6 & 4 & 2 & 0.327 \\
$\begin{array}{l}\text { Gender } \\
\quad \text { Male }\end{array}$ & 19 & 11 & 8 & 0.63 \\
$\quad$ Female & 26 & 15 & 11 & 0.73 \\
$\begin{array}{l}\text { Preoperative BMI } \\
\text { Operation time }\end{array}$ & 28.8 & 29.6 & 28.1 & 0.437 \\
(minutes) & 22.29 & 23.25 & 17.5 & 0.32 \\
\hline
\end{tabular}

score at 1 year follow-up was 3.06 and 3.56 respectively for the open and percutaneous groups, corresponding to good. Of the 45 patients, 31 (68.9\%) reported "good" to "excellent" satisfaction with the procedure overall. As for the results on expectations for the procedure, which was on a scale of $1-7$, the average score at 1 year follow-up was 2.40 and 2.10 , respectively, for the open and percutaneous groups with 35 (77.8\%) of 45 patients reporting that their expectations, at least more or less, had been met.

Twenty-six patients treated with the open procedure and 19 treated pecutaneously. The demographics for both groups were comparable preoperatively. There was no significant difference with regard to postoperative SF-36 scores between the two groups at 3 months, 6 months, and 1 year follow-up (Figs 5 to 7). However, the open RF microtenotomy group had better HINDVAS scores at 3 months postoperatively. The difference was statistically significant (HINDVAS, 3.10 vs $4.53, p=0.027$ ). There was no difference between the two groups at 6 months and 1 year follow-up. The open RF microtenotomy group also had a better AOFAS hindfoot score both at 3 months (HINDTOT, 68.75 vs 59.56, $p=0.015$ ) and at 6 months (HINDTOT, 80.94 vs $69.45, p=0.01$ ) postoperatively. There was no significant difference at 1 year follow-up (Table 4).

No infections, neurovascular injuries, deep venous thrombosis, or perioperative medical complications were noted throughout the follow-up period. There was one case who had persistent pain postoperatively in the open microtenotomy group that required pain management intervention. The patient subsequently made an uneventful recovery. No cases of lateral column pain or arch collapse were noted on final follow-up. No reoperations were done in both groups.

\section{Discussion}

Chronic plantar fasciitis is often a self-limiting condition that can be treated with conservative treatment in almost $90 \%$ of patients. It is known that plantar fasciitis is similar to a tendinosis but is noninflammatory and associated with overuse. ${ }^{14,15}$ Radiofrequencybased microtenotomy using TOPAZ coblation for the treatment of plantar fasciitis has been found to be effective in stimulating an angiogenic healing response in fascial tissue. Early inflammatory response, new vessel formation, and elevated vascular endothelial growth factor were shown to be part of the process. ${ }^{16,17}$

There are studies which clearly show a positive association between plantar fasciitis and obesity. ${ }^{18-21}$ There has been no clear biomechanical explanation on whether this might be due 
Table 3: Both groups showed statistically significant improvements in visual analog scale (VAS) and American Orthopedic Foot and Ankle Society (AOFAS) scores

\begin{tabular}{|c|c|c|c|c|c|}
\hline & Preoperative & $\begin{array}{l}3 \text { months' } \\
\text { postoperative }\end{array}$ & 6 months & 1 year & $p$ value \\
\hline \multicolumn{6}{|l|}{ VAS score } \\
\hline Open RF microtenotomy & 7.91 & 3.10 & 2.42 & 2 & $<0.01$ \\
\hline Percutaneous RF microtenotomy & 7.56 & 4.53 & 3.37 & 2.1 & $<0.01$ \\
\hline \multicolumn{6}{|l|}{ AOFAS hindfoot } \\
\hline Open RF microtenotomy & 40.86 & 68.75 & 80.94 & 86.2 & $<0.01$ \\
\hline Percutaneous RF microtenotomy & 41.06 & 59.56 & 69.45 & 83.32 & $<0.01$ \\
\hline
\end{tabular}

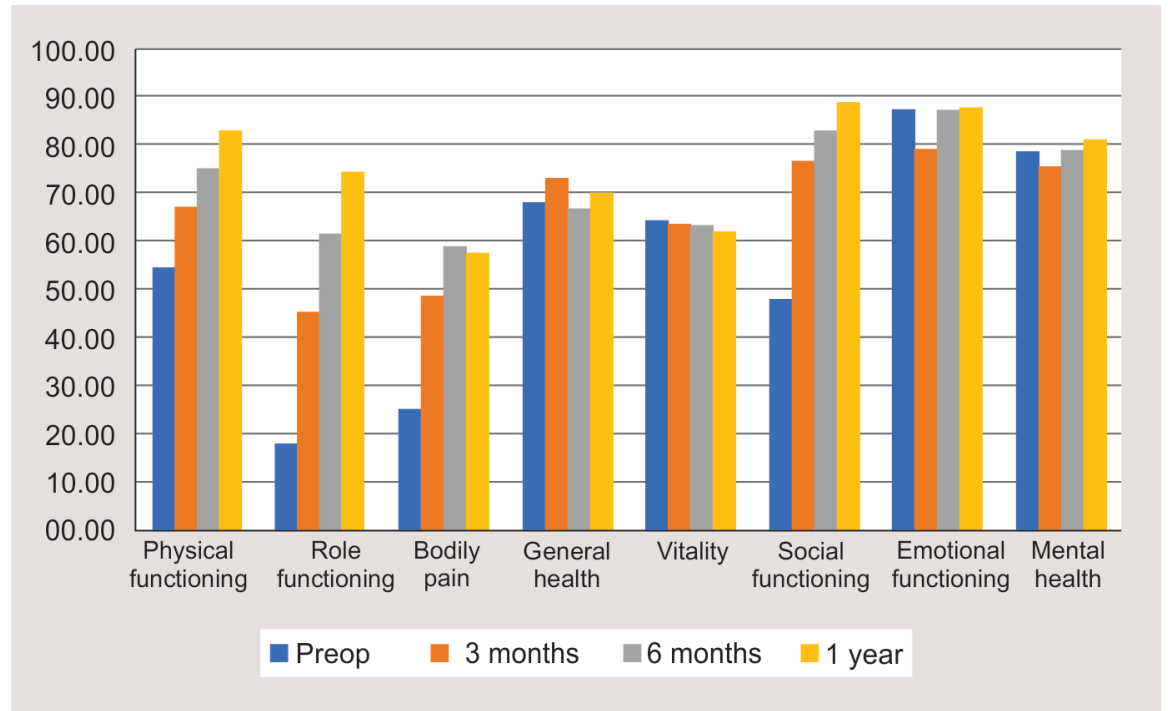

Fig. 3: SF36 scores for percutaneous radiofrequency microtenotomy

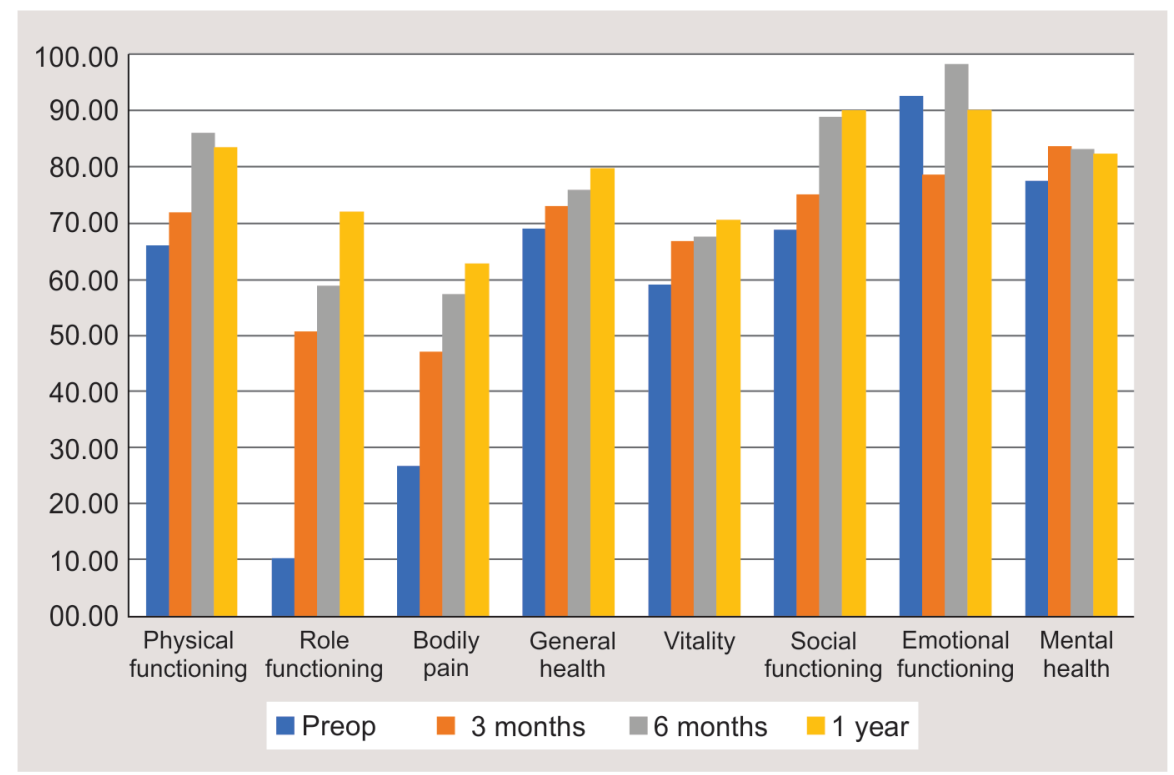

Fig. 4: SF36 scores for open radiofrequency microtenotomy

to increased stress loading on the plantar fascia, leading to microdamage and degeneration for patients who are overweight and obese as compared to their leaner counterparts. However, when comparing the breakdown of high BMI to that of a high fat mass group and fat-free mass group (high muscle mass), foot pain is more strongly associated with fat mass rather than fat-free mass, therefore, suggesting another pathway such as adiposity-related inflammatory mechanisms that might play a role in the relationship between a high BMI and plantar fasciitis. ${ }^{22,23}$ When associating obesity with the heel fat pad, it has been shown that heel pad 


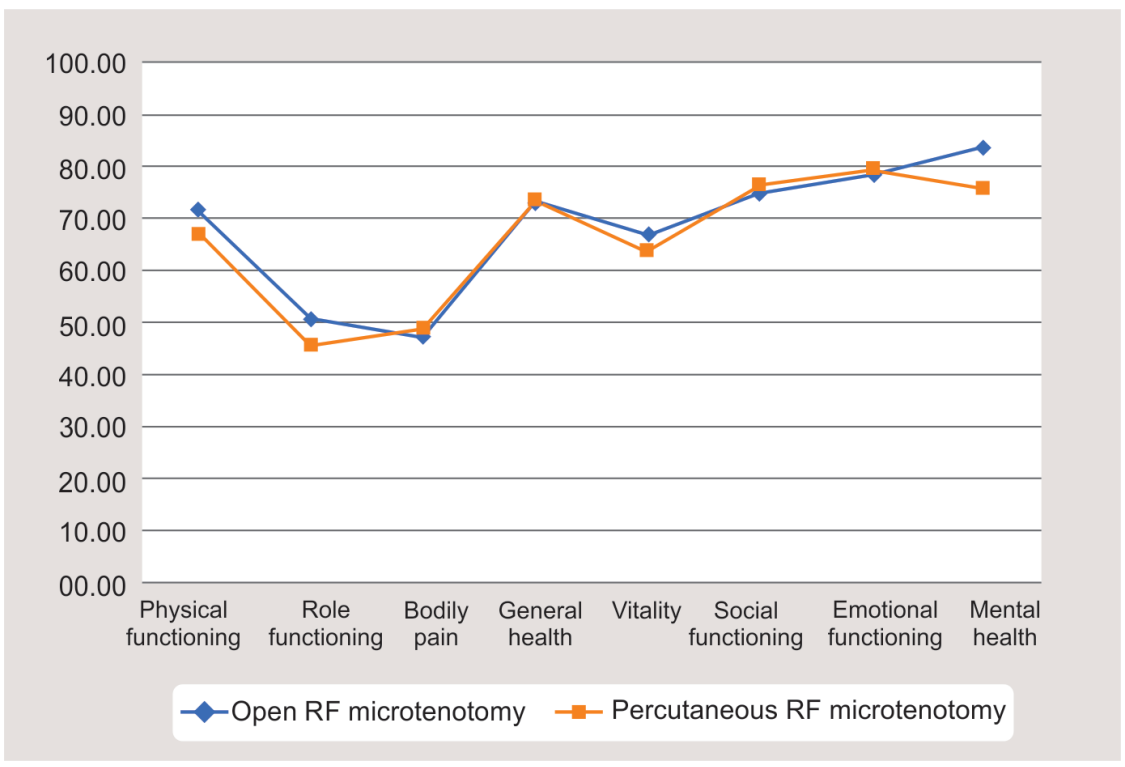

Fig. 5: No statistically significant difference for SF-36 scores between the two groups at 3 months postoperative

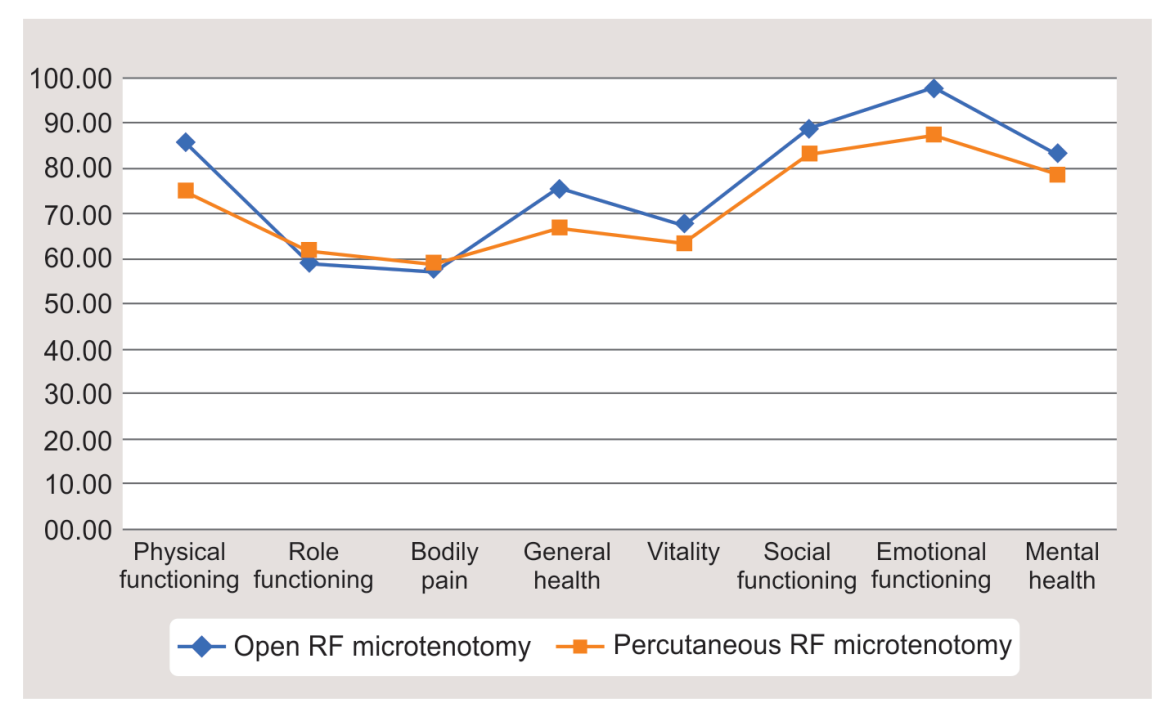

Fig. 6: No statistically significant difference for SF-36 scores between the two groups at 6 months postoperative

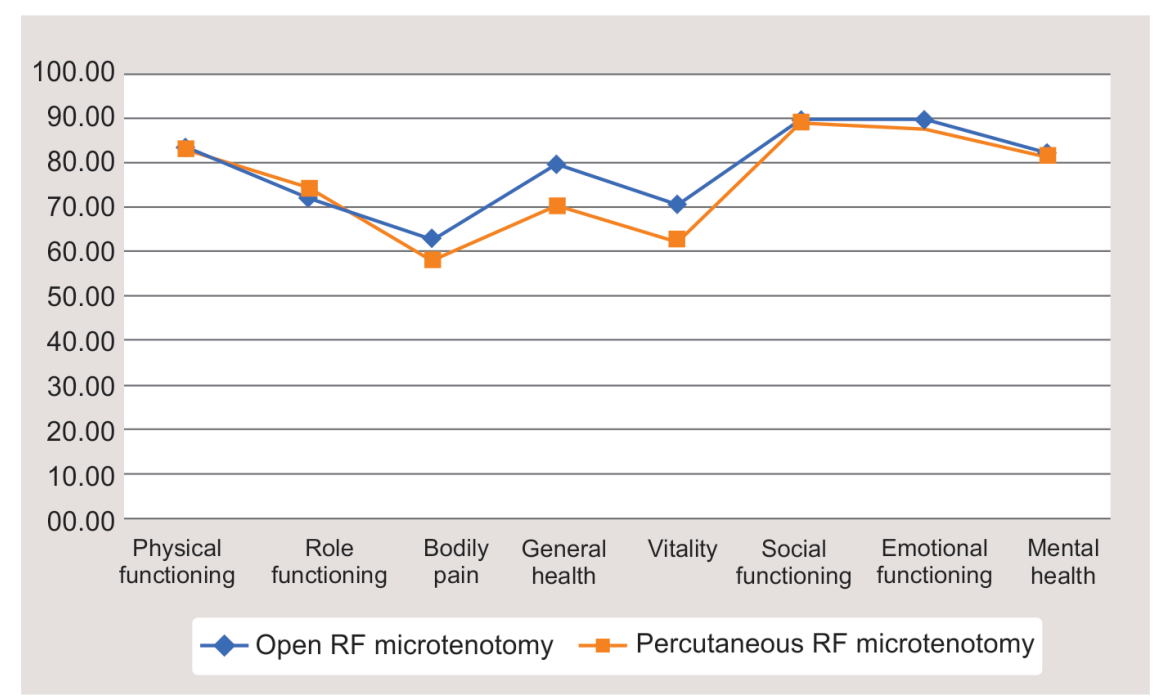

Fig. 7: No statistically significant difference for SF-36 scores between the two groups at 1 year postoperative 
Open vs Percutaneous TOPAZ Coblation for the Management of Plantar Fasciitis

Table 4: Patient outcomes

\begin{tabular}{lccl}
\hline Outcomes & Open $(n=26)$ & $\begin{array}{l}\text { Percutaneous } \\
(n=19)\end{array}$ & p value \\
\hline $\begin{array}{l}\text { Preoperative } \\
\text { HINDVAS }\end{array}$ & 7.91 & 7.56 & 0.355 \\
HINDTOT & 40.86 & 41.06 & 0.565 \\
Postoperatively & months & & \\
EXP & 3.153 & 3.174 & 0.228 \\
SAT & 3.86 & 4.1 & 0.21 \\
HINDVAS & 3.1 & 4.53 & 0.027 \\
HINDTOT & 68.75 & 59.56 & 0.015 \\
6 months & & & \\
EXP & 2.857 & 3.107 & 0.192 \\
SAT & 3.16 & 3.85 & 0.165 \\
HINDVAS & 2.42 & 3.37 & 0.198 \\
HINDTOT & 80.94 & 69.45 & 0.01 \\
1 year & & & \\
EXP & 2.4 & 2.1 & 0.816 \\
SAT & 3.06 & 3.56 & 0.654 \\
HINDVAS & 2 & 2.1 & 0.336 \\
HINDTOT & 86.2 & 83.32 & 0.55 \\
\hline
\end{tabular}

thickness was significantly greater in patients with plantar fasciitis. Some studies have also demonstrated greater compressibility of the heal fat pad in people with plantar fasciitis that controls. ${ }^{24,25}$

This study is the first to analyze the effectiveness of RF coblation for chronic plantar fasciitis in a patient population consisting solely of overweight and obese individuals. As prior studies have shown a correlation between heel pain and body weight, it would be expected that chronic plantar fasciitis would be common in this patient population. Also it might be expected that in this group of overweight or obese patients, conservative treatment of plantar fasciitis has not been as successful as in the normal population. ${ }^{26}$ When comparing the outcomes of surgical intervention, studies suggest that obesity does not predict poor outcome with endoscopic plantar fascia release. ${ }^{27}$ Our results show that RF coblation is an effective modality in treating plantar fasciitis, with an overall satisfaction rate of $68.9 \%$ and meeting expectations of $77.8 \%$ of the patients at 1 year follow-up. Functional scores improved as well, with significant improvements in both pain scores and AOFAS hindfoot scores. In addition, patients reported better quality of life as measured by the SF36 questionnaire, in several components.

This study is also the first to compare the open technique vs the minimally invasive percutaneous technique of RF microtenotomy in the subset of overweight and obese patients. Previous studies have reported that the open technique is superior in terms of outcome at 1 year follow-up, with a significantly reduced pain score compared to the percutaneous technique. ${ }^{9}$ A patient with a high BMI may present with different hindfoot biomechanics, hence resulting in different plantar pressures on standing and with ambulation. Furthermore, we postulate that these patients may also have different heel fat pad thickness or compressibility as compared to a patient with a BMI within the normal range. We also aim to find out whether complications such as wound healing or prolonged pain or recurrent pain would be affected by the patient's BMI.

Our study findings show that the open technique results in better HINDVAS scores at 3 months' follow-up and better HINDTOT scores at both 3 and 6 months' follow-up. There was no difference in both pain and functional scoring at the 1 year mark. It would be interesting to note that a bigger wound in the open group did not subsequently lead to poorer pain scores in the early stages of follow-up. As mentioned previously, chronic plantar fasciitis is a form of tendinosis, for which there is an absence of inflammatory cells. Fibroplasia hypertrophy with disorganized vascular hyperplasia dominates with avascular tendon fascicles. It is unlikely that the early improvements can be due to the revascularization and even reorganization of collagen in the treated tendons. An antinociceptive effect, similar to that produced by extracorporeal shock wave therapy, may be a plausible explanation. ${ }^{28-31}$ This may be affected by the level of accuracy at which the probe is able to target the symptomatic portion of the fascia. The open technique allows better visualization and accurate placement of the microtenotomy probe on the area of the fascia that was most symptomatic. In contrast, the depth of placement of the probe in the percutaneous technique may be affected by a number of variables, including soft tissue swelling and also thickness of the skin. As such, the amount of stimulation received by the fascia will be variable and most likely less than that provided by the open technique. To overcome this disadvantage, Shah et al. in his article described a novel method of performing the percutaneous procedure under ultrasound guidance. ${ }^{32}$ Our results show that in both groups, there is a plateauing of improvement in both pain and functional scoring at the 1 year follow-up mark. This is probably due to the short-lived antinociceptive effect being replaced by a longer-term angiogenic response, which was not affected whether the procedure was done in open or in the percutaneous manner.

One possible negative effect of the RF-based microtenotomy procedure would be potential excessive adjacent tissue damage. ${ }^{33-}$

${ }^{35}$ There is also always a risk cutting the plantar fascia, leading to the risk of rupture. We postulate that an open procedure with direct visualization of the plantar fascia would lead to a more precise and safe placement of the probe during the microtenotomy procedure. Our results show no difference in complications between both groups with no increase in wound complications or infection in the open technique group or increased occurrence of residual pain in the percutaneous group.

There are limitations to this study. First, as this is a retrospective study of prospectively collected data, there would be some inherent biases. Despite all treatment options being discussed with the patients before the operative procedure and having noted no difference in the demographics between both groups, there were a disproportionate number of patients in both groups which could inevitably be due to selection bias. Second, we have excluded patients without a full data set, and this may have included patients who missed their follow-ups. This could lead to a selection bias of results from the group of patients who were able to attend clinic appointments. However, the strengths of the study include the fact that this is one of the few or if not the first study to investigate the use of RF microtenotomy treatment on the subset of obese patients. We have a modest number of patients in our study groups with a good follow-up of 1 year.

\section{Conclusion}

We have shown that RF microtenotomy is a safe and effective procedure for the treatment of plantar fasciitis even in the obese group of patients. Both open and percutaneous methods have achieved good patient outcomes and expectation, although the open group showed superior pain and functional outcomes 
at 3 and 6 months' follow-up. Larger, randomized, prospective studies with a longer follow-up period are needed to fully compare the postoperative outcomes of open vs percutaneous RF microtenotomy in this specialized subset of patients.

\section{Acknowledgment}

The authors would like to thank the Orthopaedic Diagnostic Centre, Singapore General Hospital for its help in data collection.

\section{References}

1. Rome K, Howe T, Haslock I. Risk factors associated with the development of plantar heel pain in athletes. The Foot 2001;11(3): 119-125. DOI: 10.1054/foot.2001.0698.

2. Lemont $H$, Ammirati KM, Usen N. Plantar fasciitis. A degenerative process (fasciosis) without inflammation. J Am Podiat Med Associat 2003;93(3):234-237. DOI: 10.7547/87507315-93-3-234.

3. Crawford F, Thompson CE. Interventions for treating plantar heel pain. Cochrane Database Syst Rev 2003;3(3):CD000416. DOI: 10.1002/14651858.CD000416.

4. Sammarco GJ, Helfrey RB. Surgical treatment of recalcitrant plantar fasciitis. Foot Ankle Int 1996;17(9):520-526. DOI: 10.1177/107110079601700902.

5. Cheung JT, An KN, Zhang M. Consequences of partial and total plantar fascia release: a finite element study. Foot and Ankle International 2006;27(2):125-132. DOI: 10.1177/107110070602700210.

6. Cheung JT, An KN, Zhang M. Effects of plantar fascia stiffness on the biomechanical responses of the ankle-foot complex. Clin Biomechan (Bristol Avon) 2004;19(8):839-846. DOI: 10.1016/j. clinbiomech.2004.06.002.

7. Weil L, Glover JP, Weil LS. A new minimally invasive technique for treating plantar fasciosis using bipolar radiofrequency: a prospective analysis. Foot Ankle Specialist 2008;1(1):13-18. DOI: 10.1177/1938640007312318.

8. Sean NY, Singh I, Wai CK. Radiofrequency microtenotomy for the treatment of plantar fasciitis shows good early results. Foot Ankle Surg 2010;16(4):174-177. DOI: 10.1016/j.fas.2009.10.008.

9. Tay KS, Ng YC, Singh IR, et al. Open technique is more effective than percutaneous technique for TOPAZ radiofrequency coblation for plantar fasciitis. Foot Ankle Surg 2012;18(4):287-292. DOI: 10.1016/ j.fas.2012.05.001.

10. Frey C, Zamora J. The effects of obesity on orthopaedic foot and ankle pathology. Foot Ankle Int 2007;28(9):996-999. DOI: 10.3113/ FAl.2007.0996.

11. Van Leeuwen KD, Rogers J, Winzenberg $T$, et al. Higher body mass index is associated with plantar fasciopathy/'plantar fasciitis': Systematic review and meta-analysis of various clinical and imaging risk factors. Br J Sports Med 2016;50(16):972-981. DOI: 10.1136/ bjsports-2015-094695.

12. Woloszko J, Kwende MM, Stalder KR. Coblation in otolaryngology. Proc SPIE 2003;4949:341-352.

13. Neufeld SK, Cerrato R. Plantar fasciitis: evaluation and treatment. J Am Acad Orthop Surg 2008 June;16(6):338-346. DOI: 10.5435/00124635200806000-00006.

14. Almekinders LC. Tendinitis and other chronic tendinopathies. J Am Acad Orthop Surg 1998;6(3):157-164. DOI: 10.5435/00124635199805000-00003.

15. Tasto JP, Cummings J, Medlock V, et al. Microtenotomy using a radiofrequency probe to treat lateral epicondylitis. Arthroscopy 2005;21(7):851-860. DOI: 10.1016/j.arthro.2005.03.019.

16. Harwood R, Bowden K, Amiel M, et al. Structural and angiogenic response to bipolar radiofrequency treatment of normal rabbit achilles tendon: a potential application to the treatment of tendinosis. Trans Orthop Res Soc 2003;28:819.

17. Medlock VB, Amiel D, Harwood F, et al., Angiogenic response to bipolar radiofrequency treatment of normal rabbit Achilles tendon. In: Presented at the Congress of ISAKOS; 2003.

18. Riddle DL, Pulisic M, Pidcoe P, et al. Risk factors for plantar fasciitis: a matched case-control study. J Bone Jt Surg Ser A 2003;85(5):872-877. DOI: 10.2106/00004623-200305000-00015.

19. Irving DB, Cook JL, Young MA, et al. Obesity and pronated foot type may increase the risk of chronic plantar heel pain: a matched case-control study. BMC Musculoskelet Disord 2007;8(1):41. DOI: 10.1186/1471-2474-8-41.

20. Prichasuk S, Subhadrabandhu T. The relationship of pes planus and calcaneal spur to plantar heel pain. Clin Orthop Relat Res 1994(306):1926.

21. Turgut A, Göktürk E, Köse N, et al. The relationship of heel pad elasticity and plantar heel pain. Clin Orthop Relat Res 1999(360): 191-196. DOI: 10.1097/00003086-199903000-00023.

22. Butterworth PA, Landorf KB, Smith SE, et al. The association between body mass index and musculoskeletal foot disorders: a systematic review. Obes Rev 2012;13(7):630-642. DOI: 10.1111/j.1467789X.2012.00996.x.

23. Tanamas SK, Wluka AE, Berry P, et al. Relationship between obesity and foot pain and its association with fat mass, fat distribution, and muscle mass. Arthritis Care Res (Hoboken) 2012;64(2):262-268. DOI: 10.1002/acr.20663.

24. Karabay N, Toros $\mathrm{T}$, Hurel $\mathrm{C}$. Ultrasonographic evaluation in plantar fasciitis. J Foot Ankle Surg 2007;46(6):442-446. DOI: 10.1053/ j.jfas.2007.08.006.

25. Alvarez-Nemegyei J, Negreros-Castillo A. Risk factors for plantar talalgia in nonathletes: a case-control study. J Clin Rheumatol 2000;6(4):189-193. DOI: 10.1097/00124743-200008000-00004.

26. Hill JJ, Cutting PJ. Heel pain and body weight. Foot Ankle 1989;9(5):254-256. DOI: 10.1177/107110078900900509.

27. Lundeen RO, Aziz SA, Burks JB, et al. Endoscopic plantar fasciotomy: a retrospective analysis of results in 53 patients. J Foot Ankle Surg 2000;39(4):208-217. DOI: 10.1016/s1067-2516(00)80002-2.

28. Birnbaum K, Wirtz DC, Siebert CH, et al. Use of extracorporeal shock wave therapy (ESWT) in the treatment of non-unions. A review of the literature. Arch Orthop Trauma Surg 2002;122(6):324-330. DOI: 10.1007/s00402-001-0365-4.

29. Haake $M$, Thon A, Bette M. No influence of low energy extracorporeal shock wave therapy (ESWT) on spinal nociceptive systems. J Orthop Sci 2002;7(1):97-101. DOI: 10.1007/s776-002-8429-0.

30. Heller KD, Niethard FU. Using extracorporeal shock wave therapy in orthopaedics - a meta analysis. Z Orthop Ihre Grenzgeb 1998;136(5):390-401. DOI: 10.1055/s-2008-1053674.

31. Vale ML, Marques JB, Moreira CA, et al. Antinociceptive effects of interleukin-4, -10 , and -13 on the writhing response in mice and zymosan-induced knee joint incapacitation in rats. J Pharmacol Exp Ther 2003;304(1):102-108. DOI: 10.1124/jpet.102.038703.

32. Shah A, Best AJ, Rennie WJ. J Ultrasound Med 2016 Jun;35(6): 1325-1331. DOI: 10.7863/ultra.15.06085.

33. Lu Y, Edwards RB, Cole BJ, et al. Thermal chondroplasty with radiofrequency energy. An in vitro comparison of bipolar and monopolar radiofrequncy devices. Am J Sports Med 2001;29(1):42-49. DOI: 10.1177/03635465010290011201.

34. Lu Y, Edwards RB, Kalscheur VL, et al. Effect of bipolar radiofrequency energy on human articular cartilage. Comparison of confocal laser microscopy and light microscopy. Arthroscopy 2001;17(2):117-123. DOI: 10.1053/jars.2001.21903.

35. Lu Y, Edwards RB, Nho S, et al. Thermal chondroplasty with bipolar and monopolar radiofrequency energy: effect of treatment time on chondrocyte death and surface contouring. Arthroscopy 2002;18(7):779-788. DOI: 10.1053/jars.2002.32840. 